\title{
Requirements of Resident Scholarly Activity
}

\author{
Richard Balon $^{1} \cdot$ Nicole Stromberg ${ }^{1}$
}

Received: 5 August 2016 / Accepted: 12 August 2016 /Published online: 22 August 2016

(C) Academic Psychiatry 2016

To the Editor:

The Accreditation Council for Graduate Medical Education (ACGME) mandates that residents become involved in scholarly activity during their training. This mandate is definitely important and thoughtful; involvement in scholarly activity during training helps to develop intellectual curiosity and critical thinking and to start a future academic career. The categories recognized as resident scholarly activity by the ACGME (in the ACGME Accreditation Data System - update of scholarly activity for each resident) include articles with PubMed identification numbers (PMIDs), conference presentations, chapters textbooks, participation in research, and teaching presentations.

Almost 11 years ago, the American Journal of Psychiatry (AJP) started to publish the Residents' Journal (AJP-RJ), which appears monthly online with the AJP [1]. Under the auspices of the AJP editor, the AJP-JR is run, peer reviewed, and edited by residents from all over the USA. It intends to serve as a forum for residents and fellows to share ideas and experiences in training, clinical practice, research, and careers with colleagues. As the current AJP-RJ editor-in-chief, Dr. Katherine Pier (a fourth-year resident at the Icahn School of Medicine, New York) writes, "The journal is a promising vehicle for medical students, residents, and fellows to author and publish manuscripts early in their careers" [2]. It also helps residents running this journal to learn the nuts and bolts of publishing a journal, such as the peer review process and

Richard Balon

rbalon@wayne.edu

1 Wayne State University, Detroit, MI, USA manuscript editing. Some editors and authors got started on the pages of the AJP-RJ and have become involved in academia and further scholarly writing (e.g., J. Cerimele, S. Fayed, M. Seawell, A. Vahabzadeh, to mention a few). The AJP-RJ seems a near-perfect vehicle for quality, well-documented resident scholarly activity to help fulfill the ACGME requirements.

Unfortunately, this is not the case. For various understandable reasons, AJP-RJ articles are not indexed in PubMed. The ACGME documentation of scholarly activity does not give credit for articles without a PMID. Some may argue that only having articles with PMIDs as documentation of scholarly activity is reasonable. We feel, however, that AJP-RJ publications are arguably at par with ACGME requirements of scholarly activity such as conference or teaching presentations. We call on the ACGME to amend the requirements of resident scholarly activity to include bona fide, well-documented activities such as articles in the AJP-RJ and similar publications.

\section{Compliance with Ethical Standards}

Disclosures On behalf of all authors, the corresponding author states that there is no conflict of interest.

\section{References}

1. Charoensook J, Sidaros R, Pier K, et al. Reflections on an innovation: the first trainee-led academic psychiatry journal. Acad Psychiatry. 2016;40:564-65.

2. Piers KS. The Residents' Journal: a 10-year journey and symbol of collaboration. Am J Psychiatry-Res J. 2016;11(7):2. 